\title{
Targeted Therapy for Renal Cell Carcinoma: a Prospective study
}

\author{
Robin Joshi,' Sudhir Rawal ${ }^{2}$ \\ 'Kathmandu Medical College, Kathmandu, Nepal ${ }^{2}$ Rajiv Gandhi Cancer Institute and Research Centre, Delhi, India
}

\section{ABSTRACT}

Introduction: Our study aims to evaluate the use of targeted therapy in metastatic renal cell carcinoma

Methods: This is a prospective study done over three years from December 2010 to December, 2013. Out of Forty seven patients of metastatic renal cell carcinoma 8(neo-adjuvant cases) were excluded and 39 were included in this study. All patients received Tyrosine kinase inhibitor, sunitinib therapy (50 mg OD, 4/2 scheme). All 39 patients underwent radical nephrectomy prior to sunitinib therapy. Patients were followed up every cycle for their clinical symptoms following sunitinib therapy and every 3 months with chest X-ray, ultra-sonography and bone scan. CT scan was done if needed. A RECIST criterion was used to evaluate the complete, partial and no tumor response.

Results: The median survival was 28.5 months (CI 9.253-47.7) and progression free survival (PFS) was 9.16 months(CI 6.08-12.23).According to RECIST, stable disease was found in 6 patients till date and a complete response in two patients. Clear cell histology was found in $30(76.9 \%)$ patients, papillary variety in $6(15.39 \%)$ patients, chromophobe type was seen in one patient and rest had mixed sarcomatoid papillary and rhabdoid clear cell variety. Twenty four patients $(61.5 \%)$ had multiple metastases. Most frequent metastasis was seen in lungs in 14 patients (36\%) and bone in 12 patients $(31 \%)$.Metastases were also seen in draining lymph nodes, adrenals, omentum,skin, liver, and brain.

Conclusions: In our cohort, use of sunitinib showed similar outcome to previously published articles. Our study supports the use of sunitinib in metastatic renal cell carcinoma.

Keywords: metastatic renal cell carcinoma; sunitinib; tyrosine kinase inhibitor.

\section{INTRODUCTION}

Of all the kidney neoplasms, $90-95 \%$ is renal cell carcinoma (RCC) and accounts for $3 \%$ of all adult malignancy. ${ }^{1,2}$ Every year 100,000 patients die of RCC worldwide with the rate of mortality and incidence increasing by $2-3 \%$ per decade. ${ }^{1,3}$ Prognosis of metastatic RCC is grim and only $23 \%$ of patients live up to five years. ${ }^{4}$ This poor prognosis is mainly due to metastatic RCC ( $\mathrm{mRCC}$ ) being resistant to treatment with more than $25 \%$ of patients at presentation having metastasis and of these about $95 \%$ with metastases at multiple sites. ${ }^{1}$

For $\mathrm{mRCC}$, traditional therapy includes surgery of the primary and concomitant metastases when possible and immunotherapy and/or targeted therapy in patients with good performance status. ${ }^{6}$ But RCC remains a difficult disease to treat when it presents with advanced features and for this reason correct staging is crucial to further treatment. Advanced RCC has been treated historically with different cytokines \& immunotherapy like interleukin-2. Interferon alfawas also used but many patients did not tolerate the serious toxicities and only a smaller percentage of patients achieved complete response \& with less durability. ${ }^{6}$

The introduction of molecular targeted therapies like vascular endothelial growth factor (VEGF) neutralizing

Correspondence: Dr. Robin Joshi, Kathmandu Medical College, Kathmandu, Nepal. Email: robinjoshi@hotmail.com, Phone No: +9779841318312 
antibody (bevacizumab), and the VEGF receptor and platelet derived growth factor (PDGF) receptor targeted tyrosine kinase inhibitors (sorafenib, Sunitinib, pazopanib) have revolutionized the treatment of this disease. TKIs are known to have effects on tumor vascularity, angiogenesis processes and have direct effects on the tumor cells leading to significant reduction in tumor size in many cases. Sunitinib has been found to have as high as $30 \%$ partial response rate using RECIST criteria1.1 for tumor measurement and sorafenib with approximately $10 \% .^{7}$

\section{METHODS}

This is a prospective study over three years from 2010 -2013 at Rajiv Gandhi cancer institute,Delhi,India. Out of Forty seven patients with metastatic renal cell carcinoma, 8 were excluded as they received neoadjuvant sunitinib and had refused surgery. Thirty Nine patients were thus included in this study.Prior informed consent was taken after explaining about the drug, its related outcomes and complications. Ethical committee approval was also taken before the start of the study. All patients in this study received TKI, sunitinib, as first-line(50 mg, $4 / 2$ scheme) treatment. Patients underwent Radical Nephrectomy prior to sunitinib therapy.

Sunitinib was started two weeks after surgery, after removal of sutures. Patients were followed up every month and relevant investigations were performed before the start of another cycle. Complete blood count, Biochemistry, renal function test, thyroid function test were performed and sunitinib -related complications were noted. Dose adjustment $(25 \mathrm{mg}, 4 / 2$ scheme)was carried out if there were drug related complications. Hypothyroidism and hypertension were treated symptomatically after consultation with the physician. Chest X-ray and Ultrasound(USG)of abdomenand pelvis were doneevery three months with CT scan of abdomen and chest as required after evaluating chest $\mathrm{x}$-ray and USG.

RECIST criteria version 1.1 was used to evaluate the overall tumor response like stable disease,complete/ partial response, and recurrence. Patients' death, progression of disease and change to other TKI were also noted. Patients' characteristics like age, sex, tumor presentation, site of metastasis and histological types were recorded. Drug related side-effects, number of drug dose cycles, and need of drug adjustments according to the complications were also noted for statistical evaluation.

\section{Statistics:}

Statistical package for the social sciences (SPSS) ver. 12 (SPSS, Inc., Chicago, IL) was used for the statistical
analysis.Progression free survival(PFS) and overall survival (OS) were plotted using Kaplan Meir graph.

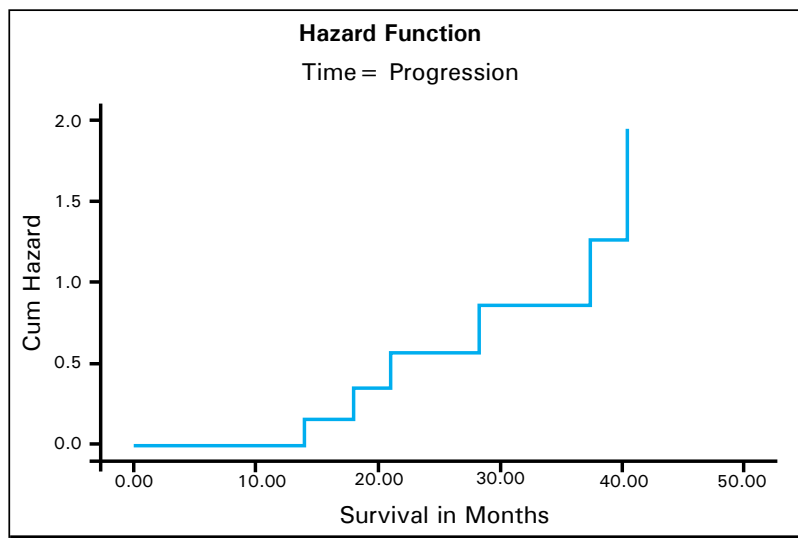

Figure 1. Kaplan Meier survival Analysis and progression of disease for patients on Sunitinib.

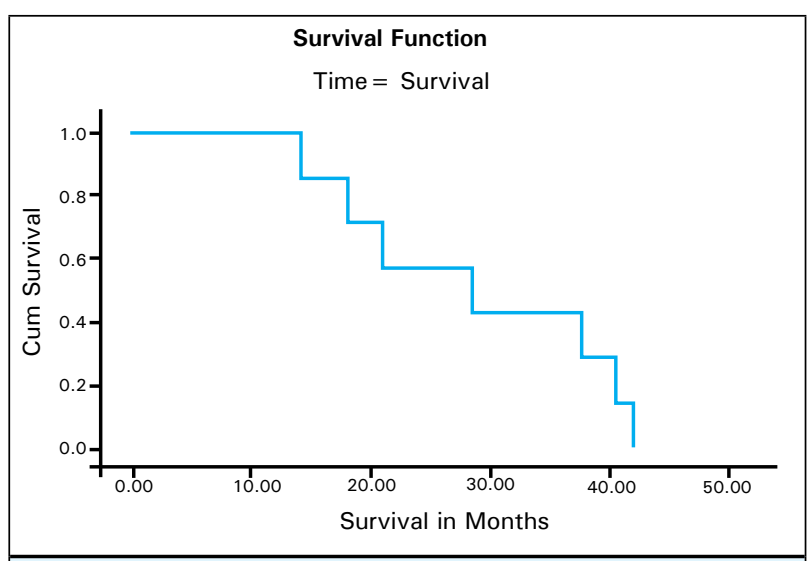

Figure 2. Kaplan Meier estimate of survival in months.

\section{RESULTS}

Forty seven patients with mRCC were treated with Sunitinib.Eight patients had received sunitinib as neoadjuvant therapy and were excluded from the study. Thirty nine patients received $50 \mathrm{mg}$ sunitinib per day for four weeks on and two weeks off scheme. The age of the patients ranged from $31-80$ years and there were 33 male(76.9\%) and nine female(23.1\%) patients. One to twenty seven cycles of sunitinib were prescribed for a median of four cycles and mean of 5.2 cycles(Table 3).Majority of the cases presented with primary tumor symptoms like pain/heaviness and mass at hypochondriac region while some patients had metastatic tumor symptoms like back/bony pain,loss of weight and appetite, cough and two patients presented with paraparesis. Right kidney(n-25,64.1\%) involvement wascommon(Table1).

The median survival was 28.5 months $(\mathrm{Cl}$ 9.25347.7) and progression free survival (PFS) was 9.16 months $(\mathrm{Cl}$ 6.08-12.23)(Graph1,2).According to RECIST1.1, stable disease was found in six patients till date and a complete response in two patients. 
Calculation of expected increase in PFS and median OS is not possible in this study as we concluded the study after three years. Clear cell histology was found in 30 (76.9\%) patients, papillary variety in six $(15.39 \%)$ patients, chromophobe type was seen in one patient and rest had mixed sarcamatoid papillary and rhabdoid clear cell variety. Twenty four patients $(61.5 \%)$ had multiple metastases. Most frequent metastasis was seen in lungs in 14 patients $(36 \%)$ and bone in 12 patients (31\%).Metastases were also seen in draining lymph nodes, adrenals, omentum, skin, liver, brain (Table1). Majority of the patients experienced generalized weakness $(51.28 \%)$ and commonest side effects seen were hand to mouth syndrome(35.89\%), hypothyroidism(25.64\%), skin lesions(25.64\%) and hyponatremia (17.94\%)(Table 2). Thrombocytopenia, hypertension and diarrhea were observed in $12 \%$, $5.1 \%$, and $7.6 \%$ respectively (Table 2 ).

\begin{tabular}{|c|c|c|}
\hline Characteristics & Number of patients ( $\mathrm{n}$ ) & Percentage (\%) \\
\hline \multirow{2}{*}{$\begin{array}{l}\text { Total patients } \\
\text { Median age(yrs) } \\
\text { Range }\end{array}$} & 39 & \\
\hline & $31-80$ yrs & \\
\hline \multicolumn{3}{|l|}{ Sex } \\
\hline Male & 30 & $76.9 \%$ \\
\hline Female & 9 & $23.1 \%$ \\
\hline \multicolumn{3}{|l|}{ Presentation } \\
\hline \multicolumn{2}{|l|}{ symptoms } & \\
\hline $\begin{array}{l}\text { Metastatic tumor } \\
\text { Symptoms }\end{array}$ & $\begin{array}{l}\text { Back /bony pain, loss of weight, apetite, cough, } \\
\text { paraperesis }\end{array}$ & \\
\hline Site & Right kidney(25) & $64.1 \%$ \\
\hline \multicolumn{3}{|l|}{ Metastatic sites } \\
\hline Lung & 14 & $36 \%$ \\
\hline Bone & 12 & $31 \%$ \\
\hline Lymphadenopathy & 5 & \\
\hline Omentum & 2 & \\
\hline Adrenal & 3 & \\
\hline Liver & 1 & \\
\hline Skin & 2 & \\
\hline Brain & 1 & \\
\hline Thrombus & RV 2, IVC 3, It atrium & \\
\hline \multicolumn{3}{|l|}{ sites(metastases) } \\
\hline$>1$ & 24 & $61.5 \%$ \\
\hline 1 & 15 & \\
\hline \multicolumn{3}{|l|}{ Histology } \\
\hline Clear cell & 30 & $76.9 \%$ \\
\hline Papillary & 6 & $15.39 \%$ \\
\hline Chromophobe & 1 & \\
\hline \multicolumn{3}{|l|}{ Sarcomatoid } \\
\hline With papillary & 2 & \\
\hline clear cell & 1 & \\
\hline rhabdoid with clear cell & 1 & \\
\hline
\end{tabular}

Treatment Delivered. 
Joshi et al. Targeted Therapy for Renal Cell Carcinoma: a Prospective study

\begin{tabular}{|c|c|c|c|c|c|}
\hline \multirow[t]{2}{*}{ Complication } & \multirow[t]{2}{*}{ Number of patient (n) } & \multirow[t]{2}{*}{ Percentage (\%) } & \multicolumn{3}{|c|}{ Toxicity Grade } \\
\hline & & & 1 & 2 & 3 \\
\hline Genaralized weakness & 19 & $51.28 \%$ & 19 & & \\
\hline Hyponatremia & 6 & $17.94 \%$ & 5 & 1 & \\
\hline Hand to mouth syndrome & 14 & $35.89 \%$ & 13 & 1 & \\
\hline Cytopenia & 16 & $41.02 \%$ & & & \\
\hline Neutropenia & 8 & $20.5 \%$ & 6 & & 2 \\
\hline Thrmbocytopenia & 5 & $12 \%$ & 4 & 1 & \\
\hline Anaemia & 2 & $5 \%$ & & & \\
\hline Hypothyroidism & 8 & $25.64 \%$ & 7 & 1 & \\
\hline Hypertension & 2 severe & $5.1 \%$ & 0 & & 2 \\
\hline Skin Lesions & 10 & $25.64 \%$ & 10 & & \\
\hline Diarrhoea & 3 & $7.6 \%$ & 3 & & \\
\hline
\end{tabular}

\begin{tabular}{|c|c|c|}
\hline $\begin{array}{l}\text { Number of } \\
\text { Cycles of } \\
\text { Sunitinib } \\
\text { Median }=4 \\
\text { Mean }=5.2\end{array}$ & $\begin{array}{l}\text { Number } \\
\text { of } \\
\text { Patients }\end{array}$ & $\begin{array}{l}\text { Response of Sunitinib(Using } \\
\text { Recist Criteria } 1.1 \text { ) }\end{array}$ \\
\hline 27 cycles & 1 & Stable(complete remission) \\
\hline 25 cycles & 1 & Stable(complete remission) \\
\hline 19 cycles & 1 & Stable \\
\hline 15 cycles & 1 & Stable \\
\hline 11 cycles & 1 & Stable \\
\hline 8 cycles & 1 & stable \\
\hline 6 cycles & 7 & Progression of disease \\
\hline 5 cycles & 3 & Progression of disease \\
\hline 4 cycles & 10 & Progression of disease \\
\hline 3 cycles & 8 & Progression of disease \\
\hline 2 cycles & 11 & Progression of disease \\
\hline 1 cycle & 2 & Progression of disease \\
\hline
\end{tabular}

Total 47 patients

Excluded( neoadjuvant) 8 patients

Grand total on adjuvant sunitinib (39 patients)

\section{DISCUSSION}

Renal cell carcinoma is a chemo-refractory tumor and is the most lethal of all the common urologic tumors. Approximately $40 \%$ of patients die of this disease..$^{8,9}$ Curative and/or curative intent surgical management is the choice for localized disease but about $25 \%$ will present with locally advanced and $20 \%$ to $30 \%$ will have systemic recurrence for localized disease. ${ }^{8}$ In the past few years, there has been a shift in the management of RCC with the introduction of TKI, VEGF antibodies and mTORS. A combination of surgery and targeted therapy is now being practiced increasingly for locally advanced and $\mathrm{mRCC}$ and more recently for the use of these agents inneoadjuvant settings. ${ }^{10}$ Of the several TKIs are sorafenib, sunitinib and pazopanib. In addition use ofbevacizumab, an anti VEGF antibody, was approved in combination with IFN $0 .{ }^{11}$ mTOR inhibitor,temsirolimus was approved in patients with mRCC who presented with three out of six poor prognostic risk factors and everolimus for patients who failed first line drugs like anti VEGF therapy. ${ }^{11}$

The tumor cells may secrete proangiogenic growth factors, like VEGF, PDGF, fibroblast growth factor and removing the primary tumor may remove the source of these factors and limit future metastases. The use of TKIsinhibit some effects of these factors and decrease angiogenesis within metastasis when used as a neoadjuvant or adjuvant therapy. ${ }^{10,12}$ Among TKIs, sunitinib is widely used for the treatment of mRCC.Patients on sunitinib were reported to have objective tumor response of $39 \%$ which was $6 \%$ for the IFN. Grade 3-4 toxicities observed were acceptable with neutropenia (12\%), thrombocytopenia $(8 \%)$, hypertension $(8 \%)$, diarrhea $(5 \%)$, hand to foot syndrome $(5 \%)$ in the sunitinib arm. ${ }^{14}$

As for our cohort of patients, $50 \mathrm{mg} /$ day sunitinib (4/2 week scheme) was prescribed andsimilar side effects were encountered as are reported in many studies conducted on Sunitinib. Generalized fatigue followed by hand to mouth syndrome, Hypothyroidism, Hyponatraemia were commonest among side-effects observed in our patients (table 2). In contrast to other reported studies. ${ }^{14,16}$ We observed more patients having generalized weakness, hand to mouth syndrome, skin lesions and hypothyroidism. Dose adjustments (25mg sunitinib) were made in our cases when grade three toxicities were observed and were managed conservatively for complications like fatigue, hand to mouth syndrome, hypertension and hypothyroidism. A study by Motzer RJ et al prescribed sunitinib $50 \mathrm{mg} /$ day for four weeks on \& two weeks off for six weeks cycles to patients with cytokine refractory mRCC. Objective response of $40 \%$ with partial response in 
25 out 63 patients was demonstrated and reduction in tumor size in more than $70 \%$ of patients. The grade three toxicities in the following trials were fatigue $(8-11 \%)$, nausea or diarrhea $(3 \%$ to $6 \%)$, dermatitis such as hand /foot syndrome (3\% to $7 \%)$, stomatitis ( $2 \%$ to $5 \%$ ), hypertension ( $21 \%$ to $6 \%$ ), Iymphopenia $(32 \%)$, neutopenia $(13 \%)$, anemia $(60 \%$ to $18 \%)$, and thrombocytopenia $(0 \%$ to $6 \%) .{ }^{16}$

Despite all these known complications sunitinib has shown favorable PFS and OS.The sunitinib expanded access programme which included 490 patients were given sunitinib as first line systemic therapy. This study demonstrated a PFS of 12 months and 6.5 months in prior nephrectomy and without prior nephrectomy group respectively. ${ }^{13}$ Jonasch et al. demonstrated a median PFS of 11.0 months and median OS of 25.4 months in patients treated with bevacizumab for $\mathrm{mRCC}^{14}$.In another study conducted by $\mathrm{C}$. Seidel et al. showed median PFS of 8.7 months for patients with mRCC treated with $\mathrm{TKI}$, sunitinib. ${ }^{15}$

In our analysis, patients with mRCC responded to sunitinib with favourable median PFS and OS as compared to other studies. With a median PFS of 9.16months (Cl 6.08-12.23) (range2.5-35.5), our patient cohort had reasonable median os of 28.5 months ( $\mathrm{Cl}$ 9.253-47.7) (Graph 1,2). Six of the total patients are still on sunitinib with stable disease and two having complete response.PFS and median OS are expected to increase in our study. Response to sunitinib was evaluated using recently updated RECISTcriteria 1.1. ${ }^{17}$ Major common side effects were comparable with other studies and were managed conservatively without any life threatening complications. Other TKIs like pazopanib, axitinib were on pipe line by the time this study was concluded. Newer drugs are expected to show favorable and satisfactory results.

\section{CONCLUSIONS}

TKI like sunitinib is prescribed as first line treatment for metastatic RCC.Toxicities of Sunitinib are manageable. PFS and median OS are comparable and they are expected to increase as 6 patients have stable disease still on sunitinib.

\section{REFERENCES}

1. Gupta K, Miller JD, Li JZ, Russell MW, Charbonneau C. Epidemiologic and socioeconomic burden of metastatic renal cell carcinoma (mRCC): a literature review. Cancer treatment reviews. 2008 May;34(3):193-205.

2. Jemal A, Siegel R, Ward E, Hao Y, Xu J, Thun MJ. Cancer statistics, 2009. CA: a cancer journal for clinicians. 2009 JulAug;59(4):225-49.

3. Basso M, Cassano A, Barone C. A survey of therapy for advanced renal cell carcinoma. Urologic oncology. 2010 MarApr;28(2):121-33

4. NCCN clinical practice guide line in oncology. Kidney cancer V. 2, 2010, National comprehensive cancer network website. http //www.nccn.org/professionals/physicians/ pdfkidneypdf.accessed feb 2010

5. Motzer RJ, Bacik J, Mazumdar M. Prognostic factors for survival of patients with stage IV renal cell carcinoma: memorial sloan-kettering cancer center experience. Clinical cancer research : an official journal of the American Association for Cancer Research. 2004 Sep 15;10(18 Pt 2):6302S-3S.

6. Ather $\mathrm{MH}$, Masood N, Siddiqui T. Current management of advanced and metastatic renal cell carcinoma. Urology journal. 2010 Winter;7(1):1-9.

7. Motzer RJ, Hutson TE, Tomczak P, Michaelson MD, Bukowski $\mathrm{RM}$, Rixe $\mathrm{O}$, et al. Sunitinib versus interferon alfa in metastatic renal-cell carcinoma. The New England journal of medicine. 2007 Jan 11;356(2):115-24.
8. Janzen NK, Kim HL, Figlin RA, Belldegrun AS. Surveillance after radical or partial nephrectomy for localized renal cell carcinoma and management of recurrent disease. The Urologic clinics of North America. 2003 Nov;30(4):843-52.

9. Lane BR, Rini BI, Novick AC, Campbell SC. Targeted molecular therapy for renal cell carcinoma. Urology. 2007 Jan;69(1):3-10.

10. Bex A, Jonasch E, Kirkali Z, Mejean A, Mulders P, Oudard S, et al. Integrating surgery with targeted therapies for renal cell carcinoma: current evidence and ongoing trials. European urology. 2010 Dec;58(6):819-28.

11. Motzer RJ, Escudier B, Oudard S, Hutson TE, Porta C, Bracarda S, et al. Efficacy of everolimus in advanced renal cell carcinoma: a double-blind, randomised, placebo-controlled phase III trial. Lancet. 2008 Aug 9;372(9637):449-56.

12. Slaton JW, Inoue K, Perrotte P, El-Naggar AK, Swanson DA, Fidler IJ, et al. Expression levels of genes that regulate metastasis and angiogenesis correlate with advanced pathological stage of renal cell carcinoma. The American journal of pathology. $2001 \mathrm{Feb} ; 158(2): 735-43$.

13. Szczylik C, Porta C, Bracarda S, et al.(2008) Sunitinib in patients with or without prior nephrectomy in an expanded access trial of metastatic renal cell carcinoma(mRCC). J ClinOnc 2008; 26 May 20 Suppl. Abstr 5124.

14. Jonasch E, Wood CG, Matin SF, Tu SM, Pagliaro LC, Corn PG, et al. Phase II presurgical feasibility study of bevacizumab in untreated patients with metastatic renal cell carcinoma. Journal of clinical oncology : official journal of the American Society of Clinical Oncology. 2009 Sep 1;27(25):4076-81. 
15. Seidel C, Fenner M, Merseburger AS, Reuter C, Ivanyi P, Langer $\mathrm{F}$, et al. Response of renal lesions during systemic treatment with sunitinib in patients with metastatic renal cell carcinoma: a single center experience with 14 patients. World journal of urology. 2011 Jun;29(3):355-60.

16. Motzer RJ, Michaelson MD, et al. Phase 2 trials of SU11248 show antitumor activity in second line therapy for patients with metastatic renal cell carcinoma (RCC). Proc AM SocClinOncol $2005 ; 23: 4508$

17. Eisenhauer EA, Therasse P, Bogaerts J, Schwartz LH, Sargent D, Ford R, et al. New response evaluation criteria in solid tumours: revised RECIST guideline (version 1.1). European journal of cancer. 2009 Jan;45(2):228-47.

18. Gore ME, Szczylik C, Porta C, Bracarda S, Bjarnason GA, Oudard S, et al. Safety and efficacy of sunitinib for metastatic renal-cell carcinoma: an expanded-access trial. The Lancet Oncology. 2009 Aug;10(8):757-63.
19. Motzer RJ, Michaelson MD, Redman BG, Hudes GR, Wilding G, Figlin RA, et al. Activity of SU11248, a multitargeted inhibitor of vascular endothelial growth factor receptor and platelet-derived growth factor receptor, in patients with metastatic renal cell carcinoma. Journal of clinical oncology : official journal of the American Society of Clinical Oncology. 2006 Jan 1;24(1):16-24.

20. Motzer RJ, Bacik J, Murphy BA, Russo P, Mazumdar M. Interferon-alfa as a comparative treatment for clinical trials of new therapies against advanced renal cell carcinoma. Journal of clinical oncology : official journal of the American Society of Clinical Oncology. 2002 Jan 1;20(1):289-96. 